\title{
The significance of culture, tourism and leisure services in social and economic development in the NE of England.
}

\author{
JOYCE LIDDLE \\ University of Durham
}

\section{Introduction: The role of culture and tourism in economic and social regeneration}

Cultural policy has attracted increasing political attention within the last five years and tourism, leisure, sports and arts have become significant elements in achieving the overall economic and social well-being of communities. The perceived potential benefits of sport, in particular, have been used by local, national and regional authorities 'as a driver of urban regeneration alongside economic development, health, education and crime prevention in helping to achieve a wide variety of performance targets' (Coaffee and Shaw, 2003, p.45). Furthermore, as well as employing large numbers of people, the creative, cultural and tourism sectors provide opportunities for wealth creation and the economic regeneration of de-industrialised areas. Recent large scale manufacturing decline and an escalating flight of call centre jobs to India and other low wage economy areas, have led many decision makers to believe that cultural projects are the way forward in a Post-Industrial future. Cultural projects can raise the profile of a region, as well as maximising social benefits or minimising the disadvantages of fragmented approaches to regeneration. They also help to manipulate symbols and strategic rhetoric to foster an ideology of change. However, Gunton (2003, p.517) urges caution in developing projects in the absence of improved evaluation, in order to reduce the probability of uneconomic regional development projects.

Until relatively recently property development and economic forces dominated regeneration discourses, with social and cultural regeneration largely ignored. Although the physical aspects of regeneration cannot be ignored, as we still need houses, schools, roads and leisure facilities, the social costs of under development were severe. Whilst questions may be raised about how much impact or benefit cultural or arts-led regeneration can have in local communities they are increasingly used to raise a region's profile in the external world. Figure 1 shows tourism figures for the NE, and this is one area of its regional economy that elites are keen to enhance. 
Despite regular regional and financial assistance, a bleak economic landscape in the North East has been made worse by recent job losses in manufacturing, and the decline in farming and the chemical industry (Cockerill and Southern, 2000). Inward investment has increased the economic diversity of the region, but it is still an economically weak region (ONE, 1999) ${ }^{1}$, crucially affected by the whims of global capital shifts and national policies.

Figure 1 Tourist attractions in the North East of England

\begin{tabular}{|c|c|c|c|c|}
\hline \multicolumn{5}{|c|}{ Tourist attractions in the North-East with 100000 or more visitors in 1989} \\
\hline \multirow{2}{*}{ Attraction } & \multicolumn{2}{|c|}{ Visitor Numbers } & \multirow{2}{*}{$\begin{array}{l}\% \\
\text { Change } \\
\text { 1985/89 }\end{array}$} & \multirow{2}{*}{$\begin{array}{l}\text { Admission } \\
\text { Charge }\end{array}$} \\
\hline & 1985 & 1989 & & \\
\hline \multicolumn{5}{|l|}{ Museums and art galleries } \\
\hline Beamish & 289000 & 486565 & 68 & Yes \\
\hline Captain Cook’s Birth Museum & 111633 & $100000^{1}$ & -10 & Yes \\
\hline Laing Art Gallery, Newcastle & 93855 & 104229 & 11 & No \\
\hline Preston Hall Museum, Cleveland & 379787 & 462317 & 22 & No \\
\hline $\begin{array}{l}\text { South Shields Museum and Art } \\
\text { Gallery }\end{array}$ & 55000 & 139558 & 154 & No \\
\hline $\begin{array}{l}\text { Sunderland Museum and Art } \\
\text { Gallery }\end{array}$ & 174111 & 122550 & -30 & No \\
\hline \multicolumn{5}{|l|}{ Historic Properties } \\
\hline Bamburgh Castle & 82000 & 115328 & 41 & Yes \\
\hline Durham Cathedral & 341000 & $400296^{1}$ & 17 & No \\
\hline Housesteads Roman Fort & 115069 & 129032 & 12 & Yes \\
\hline
\end{tabular}

${ }^{1} 1988$ figure

Source: Creigh-Tyte and Thomas, 1989

Although the region was successful, until recently, in attracting inward investment the regional strategies now highlight knowledge businesses, indigenous growth and entrepreneurship as key growth aims. Moreover, despite claims and counter claims about the economic benefits accrued from inward investment successes, the region remains approximately where it was in the 1970s, relative to other English regions. At the same time, the jobs created have been in low paid and mainly female occupations, or in the inward investment service class. Tourism, art, sport and other creative industries have been recognised as prospective income and employment creators (Thomas and Long, 2000, pp.313-328) but Hudson and Townsend caution against an uncritical

Between 1981-6, 350,000 jobs were lost in the primary and manufacturing sectors. 
interest in the former (Hudson et al, 1992, pp633-646). Limited research exists on the types of jobs created and the impacts of such economic activities. ${ }^{2} 3$

Despite these doubts, there is a growing recognition, nationally and regionally, about the potential importance of creative industries to economic development (Department of Culture, Media and Sport, 1998, p3). ${ }^{4}$ There are many hard indicators of creative and cultural industrial growth, such as income, numbers of tourists or businesses set up and inward investment, but softer indicators are more difficult to measure, as these include aspirations, feel good factors, sense of pride in place, confidence, new skills development and community spirit amongst others. The Department of Culture, Media and Sport's Mapping Document (2001) underlined the importance of creative and cultural industries noting that 'creative industries will be a key element in the 21st Century, for businesses seeking competitive edge, to societies looking for new ways to tackle issues, and improve their quality of life (DCMS, 2001). Tessa Jowell, a former Minister, is quoted as saying 'Our continuing challenge is to provide the right environment to support and enable creative industries to thrive and maximise their contribution to the UK economy, its export earnings and reputation abroad (Jowell, 2003)

In the last two decades arts and cultural activities have become dynamic aspects of regional economies and there are positive economic, social and symbolic benefits to be accrued. Figures 2, 3 and 4 provide statistics on employment in the cultural sector across the UK, during the period 1995-1999.

There is nothing new about art and creativity being used as a tool for regeneration; civic improvements in $19^{\text {th }}$ century British cities, quite often funded by industrialists; were used to demonstrate wealth and prestige. ${ }^{5}$ Town halls, public libraries and galleries reflected civic pride in the booming industrial cities whilst today governments are investing in developing public arts such as the Tate Modern, and the Lowry Centre in Salford. Arts and culture are seen as catalysts of renewal and economic development although there is some debate over whether this is a viable strategy. Undeniably arts can bring people together and raise spirits but some artists believe that it is optimistic to assume that they will create urban renaissance. Without market prices it is impossible to fully appreciate the impact, though Throsby (2001) sees aesthetic,

Tourism was worth $£ 75$ bn in 2000; 4.7\% of GDP (Guardian, 31.12.01). Gateshead Millennium Bridge attracted 250,000 visitors in the first few months (Journal, 26.12.01)

3 Losing the bid to host the Ryder Cup in Golf in 2010 lost the NE £100m in lost revenue (Journal, 26.12.01).

4 At European level culture is seen as a major social and economic force (DCMS, 1998:34). In the UK the vast majority of the sector comprises micro businesses employing less than ten people. The creative industries generate revenues of $£ 60$,billion per annum and employ 1.4 million people (DCMS, 1998:3).

5 The North East has many examples of magnificent art galleries, museums and other buildings in its major cities of Newcastle, Sunderland and Middlesbrough. 
spiritual, social, historical, symbolic, authenticity or originality value as significant and Johnson and Thomas (1992) assessed revenue created and the multiplier effect of a museum. There are few studies which show the benefits of art and culture, or demonstrate network development, awareness of the role of arts in people's lives, image change or spatial and historical information flows.

There are countless positive impacts of cultural regeneration. Nevertheless, there are also some negative aspects. Although it can unlock creativity, imagination and innovation there are concerns that it does not make up for the shortfall in manufacturing activities. Not everyone believes that the time, personnel and other resources and costs devoted to cultural activities will bring the promised benefits. There is an accepted view in some quarters that cultural role models can help communities to become involved in arts, and one important knock-on effect would be that world-class projects might act as magnets to property development. Examples such as the Baltic Arts development in Newcastle have already been successful in attracting large, popular property development schemes.

Figure 2

Employment in the Cultural Sector (1995 and 1999)

\begin{tabular}{|l|l|l|l|l|}
\hline \multirow{2}{*}{ Main Job } & $\mathbf{1 9 9 5}$ & $\mathbf{1 9 9 9}$ & \\
\cline { 2 - 5 } & Thousands & Percentage & Thousands & Percentage \\
\hline Cultural Industries & 174 & 30.7 & 204 & 31.5 \\
\hline Cultural Occupation & 252 & 44.5 & 287 & 44.3 \\
\hline Both & 140 & 24.7 & 156 & 24.1 \\
\hline Total & $\mathbf{5 6 6}$ & $\mathbf{1 0 0 . 0}$ & $\mathbf{6 4 7}$ & $\mathbf{1 0 0 . 0}$ \\
\hline
\end{tabular}

Sources: Labour Force Survey, Spring 1995 and 1999

Figure 3

Specific employment in the Cultural Sector 1995 and 1999

\begin{tabular}{|l|l|l|l|l|}
\hline \multirow{2}{*}{ Main Job } & \multicolumn{2}{|l|}{$\mathbf{1 9 9 5}$} & $\mathbf{1 9 9 9}$ \\
\cline { 2 - 5 } & Number & $\mathbf{\%}$ & Number & \% \\
\hline Artists, graphic designers, etc & 99882 & 25.5 & 109996 & 24.8 \\
\hline Actors, stage managers, etc & 57981 & 14.8 & 68738 & 15.5 \\
\hline Musicians & 21301 & 5.4 & 29498 & 6.6 \\
\hline $\begin{array}{l}\text { Camera, sound, etc, } \\
\text { equipment operators }\end{array}$ & 48947 & 12.5 & 46781 & 10.5 \\
\hline Total & $\mathbf{2 2 8 1 1 1}$ & $\mathbf{5 8 . 2 . 0}$ & $\mathbf{2 5 5 0 1 3}$ & $\mathbf{1 0 0 . 0}$ \\
\hline $\begin{array}{l}\text { Cultural jobs as percentage } \\
\text { of all main jobs: }\end{array}$ & & $\mathbf{2 . 2 \%}$ & & $\mathbf{2 . 4 \%}$ \\
\hline
\end{tabular}

Sources: Labour Force Survey, Spring 1995 and 1999 


\section{Figure 4}

Employment in the Cultural Sector by Industry and Occupation (1995 and 1999)

\begin{tabular}{|c|c|c|c|c|}
\hline \multirow{2}{*}{ Main Job } & \multicolumn{2}{|l|}{1995} & \multicolumn{2}{|l|}{1999} \\
\hline & Number & $\%$ & Number & $\%$ \\
\hline \multicolumn{5}{|l|}{ Cultural Industries } \\
\hline $\begin{array}{l}\text { Publishing/reproduction/ } \\
\text { Recording }\end{array}$ & 40198 & 12.8 & 45696 & 12.7 \\
\hline Films & 37648 & 12.0 & 40085 & 11.1 \\
\hline Radio, TV activities & 64199 & 20.4 & 70433 & 19.6 \\
\hline Artistic/literary creat & 77656 & 24.7 & 92485 & 25.7 \\
\hline Arts $f_{c}$ & 15506 & 4.9 & 26617 & 7.4 \\
\hline Library/archive activities & 52903 & 16.8 & 47563 & 13.2 \\
\hline Museum activities & 25946 & 8.3 & 37075 & 10.3 \\
\hline Total & 314056 & 100.0 & 359954 & 100.0 \\
\hline \multicolumn{5}{|l|}{ Cultural Occupations } \\
\hline Entertainment & 47221 & 12.0 & 56939 & 12.8 \\
\hline Librarians/archivists and curator & 25835 & 6.6 & 32809 & 7.4 \\
\hline Authors, writers and journalists & 91061 & 23.2 & 98836 & 22.3 \\
\hline
\end{tabular}

The need for cultural renaissance in the NE is embodied in the NE Cultural Strategy (2001). As competition for funding between regions intensified during the 1990s there was a greater need to justify the rationale of artistic and cultural projects. The Angel of the North generated more media exposure in the first year of its life than the $£ 800,000$ it cost to build (Tyneside Vision, 2001). Usherwood et al (2000) refer to this period as one of 'creative ferocity' with one hundred and eighty public sculptures established.

Overseas experience of events such as the Winter Olympics in Lillehammer suggest a modest economic benefit with most of this confined to the tourism industry. The long-term economic benefits were certainly out of proportion to the huge costs of hosting the Games (Spilling, 1996, pp321-343). A particular problem was caused by the disappearance of the 'industrial intermezzo' of temporary, short term and entrepreneurial activity after the event. An important lesson for the NE is that costs outweighed the benefits. Nevertheless, evidence given to the author suggests that both regional and local elites are keen to stimulate and sustain the cultural and economic benefits from large-scale projects such as the Baltic or Sage Music Centre.

\section{The NE Cultural Strategy and NE Governance}

A Regional Cultural Consortium was established in 2000 to develop the NE Regional Cultural Strategy with the Chair and Board members appointed by the 
Secretary of State for Culture. Its Cultural Strategy for the NE was finalised during 2002-3 in collaboration with partner agencies, but it is also set within the national framework of cultural, tourism and arts policy.

Culture is also an important feature of the Regional Economic Strategy, as part of the RDA's Cluster Development Programme for Creative and Cultural industries. This as the result of a mapping exercise, and there have been many initiatives aimed at helping entrepreneurs to set up businesses ${ }^{6}$. However, these support mechanisms were created on the assumption that these sectors of the economy are readily identifiable, or that each artist or creative person required the same levels of support. In practice, the sector is complex, disparate and fragmented with no real infrastructure in place. Moreover, there is no single agency responsible for developing the economic aspects of creative industries, because the Small Business Service lacks in depth knowledge of the sector and other agencies lack an understanding of the myriad of interactions between creative people.

Tourism is not part of the remit of DCMS regional offices, but remains firmly in the hands of the Regional Development Agencies (RDAs). This has caused an almighty fracas in the North East as it was recently announced that the roles and responsibilities of Northumbria Tourist Authority (NTA) would be taken over by the RDA (One North East). The NTA mounted a region-wide campaign, fully supported by the media, to resist this takeover and there were huge efforts to lobby Government Ministers and high profile people in the artistic, cultural and tourism sectors. So far the battle is far from settled whilst NTA claim to be one of the most successful tourist bodies in the UK.

One North East has set up a creative and cultural industries cluster, and Figure 5 shows how the North East Cultural Strategy fits into the current governance framework of the region. Oakely et al (2001, p.413) suggest that most European governments (especially the UK) are actively promoting clusters, but warn against the founding any regional policy on artificially induced clusters based on false assumptions that linkage relationships will enhance economic efficiency. Backlund and Sandberg (2002, p.90) suggest that it is by no means clear how new media activities are preferable to other forms of economic activity in a region, which themselves might be more sustainable or better address the specific development problems of an area. Interest focused on a few successful sites has obscured wider questions regarding the spatial and geographical distribution of newer (in this case, media) industries. Regions that do not enjoy support from an institutional and cultural environment provided by big cities and universities need to identify options, as well as provide strategic efforts in networking and central co-ordination.

\footnotetext{
${ }^{6}$ ISIS Arts, New Writing North and the Northern Cultural Skills Partnership are three such initiatives.
} 
Figure 5

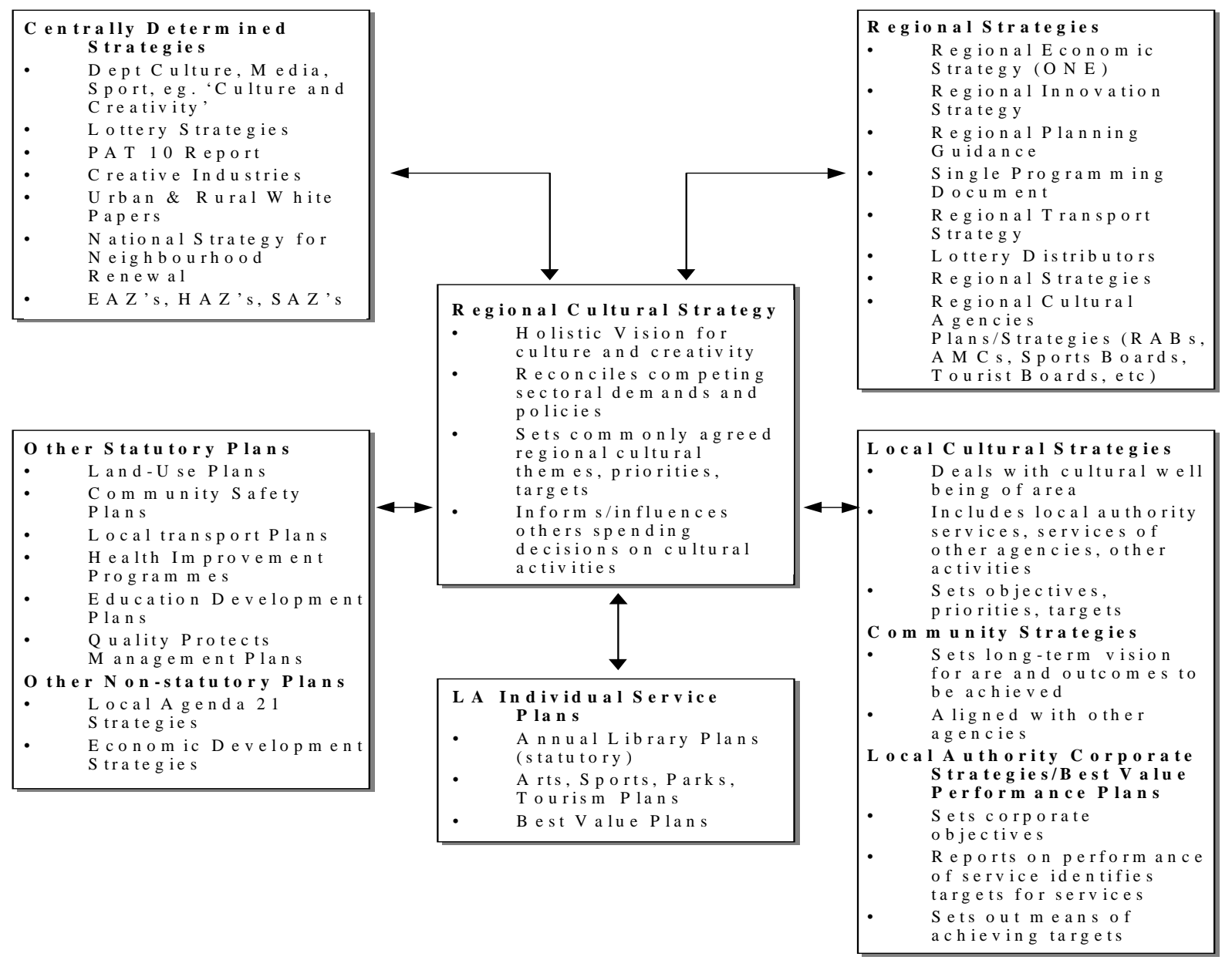

\section{Sub-Regions and Cultural Industries}

The NE is unique in devolving $75 \%$ of its RDA budget to four sub-regions; these are County Durham, Northumberland, Tees Valley and Tyne and Wear. The County Durham Strategic Partnership involves over fifty multi-agency partners and is responsible for developing a strategy for the sub-region. Initially the strategy was based on economic objectives and the County agreed to a three year Action Plan to achieve certain key outcomes that would improve the competitiveness of the sub-region. However, since these NE sub-regional partnerships were established, central government has also identified 88 areas of multiple deprivation across England (based on 33 indicators of the Index of Multiple Deprivation), and within the county there are 7 impoverished districts, where NRFunding has led to the setting up of Local Strategic Partnerships ${ }^{7}$. Because the County signed a concordat with the districts to administer the

\footnotetext{
${ }^{7}$ Local Strategic Partnerships have now been established in the County's non-NRF districts, with the objective of developing Community Strategies.
} 
funding, recent strategies have incorporated socio/cultural, as well as economic objectives.

The County Durham Economic Partnership has developed a delivery plan for the next three years (bringing together Single Programme and European funding streams), but also has available capital feasibility, the Targeted Communities Delegated Grant, and Rural Tourism Funds. Cultural and creative aspects of regeneration are now discussed as important elements of wealth and job creation ${ }^{8}$, and flagship tourism developments have become key regional and sub-regional priorities (CDEP Update, March 2004). Tourism UK (a consultancy firm) has been commissioned to prepare a County Durham Tourism Framework, as well as a number of other feasibility plans for these flagship projects ${ }^{9}$. There are clear tensions between the different levels of governance, despite the apparent harmonisation. A recent decision by County Durham Strategic Partnership to support a visioning exercise for the City of Durham, led other district representatives to raise objections, based on the view that any stimulation of the City's economic base might be at the expense of other districts. There were concerns that Durham might draw in consumers from district retailers and thus reduce spending in specific localities.

Each of the sub-regions in the NE has its own Culture Strategy as do each of the local authorities. The need for cultural strategies was driven by the need for a physical expression of culture, because this helped to draw down funds for large scale projects, but the culture is also seen anthropologically via the meanings people put on things, how proud they are of their heritage, the different ways of life and a way of creating modernity through a change culture.

County Durham has experienced de-industrialisation on a massive scale with job losses and environmental degradation. The county has 70 local authority wards, but 68 of them lie within the country's worst deprived wards identified by the Index of Multiple Deprivation. The county is still characterised by unemployment at above the national average, poor educational attainment, deprivation, health inequalities, low economic activity, falling population, lack of dynamic service industries, and poor housing stock. It also has low levels of entrepreneurialism.

County Durham's Cultural Strategy articulates a cultural vision of the County to 'ensure that cultural activity plays a key role in the life of the county for the benefit of residents and visitors', and the Economic Development Strategy of both county and district level local authorities have committed themselves to investment to local tourism and cultural development. In the belief that job creation and income generation should be at the forefront of regeneration, cultural and tourism sectors are important, but many factors are

\footnotetext{
${ }^{8}$ The author is a member of County Durham Strategic Partnership, County Durham Economic Regeneration Partnership and two district Local Strategic Partnerships.

${ }^{9}$ Including Weardale Railway, Beamish and Bowes Museums, a national cycle centre at Hamsterley.
} 
affecting the local economy, such as low educational attainment, severe health problems, high levels of deprivation, high crime rates, low levels of entrepreneurship

\section{A vision for the City of Durham: World Heritage Centre}

The City of Durham is famous as a World Heritage site because of the Castle and Cathedral, and annually attracts one million visitors (County Durham Strategic Partnership, 2003). Whereas tourism in the NE employs over $7 \%$ of the region's population (60,000 people), in the City of Durham 3000 jobs are supported by tourism spending on accommodation retail and catering (Northumbria Tourist Board, 1999). The City Council developed a Tourism Strategy with the aims of: Sustaining competitive advantage; supporting new and existing businesses in order to create new jobs; Attracting Inward Investment, to stimulate investment and wealth creation; and Securing additional resources. The City was recently granted £250k of Single Programme monies devolved from the Regional Development Agency, to carry out a visioning exercise and ascertain how leisure, tourism, recreation and cultural aspects of the city can impact on economic development (Durham Voices, 2004).

\section{Local Strategic Partnership and the Community Strategy}

The City of Durham is one of the few district authorities not to benefit from Neighbourhood Renewal Funding, mainly because it is considered to be an affluent district ${ }^{10}$. The City is a world heritage site, and dominated by the University and Cathedral and Castle, but the surrounding villages are former mining areas with many social and economic problems. The Learning and Skills Partnership was set up in 2003 to develop a Community Strategy and has six policy groups, of which culture is one (the others are lifelong learning, community safety, health, housing and environment, and economic and regeneration). Under the Local Government Act 2000 all local authorities have a duty to improve the economic, social and environmental well-being of their area.

A Leisure Strategy recently developed by this author on behalf of the City of Durham (Liddle, 2004) was driven by the need to satisfy the following agendas: Modernisation, Neighbourhood Renewal, Healthier Nation, Crime Reduction, and Social Exclusion. It also provides the basis for developing a holistic relationship between the departments of Regeneration, Economic Development, and Tourism. ${ }^{11}$

\footnotetext{
${ }^{10}$ See 'Liddle and Townsend (2003) for more detail on the setting up of Local Strategic Partnerships.

${ }^{11}$ A Best Value Review is on-going.
} 


\section{Aligning the City of Durham's cultural aspirations with sub-regional and regional objectives}

The City has a very disparate economic base, and apart from some small-scale inward investment it has not been successful in large-scale industrial activity. Existing businesses are small scale and need support to grow, especially those in cultural and creative sectors. Although the City has a Cathedral, Castle and University, it is far from affluent with many impoverished, former mining communities in its hinterland. It does not benefit from Neighbourhood Renewal Funding, but was still expected to create a Local Strategic Partnership for developing a Community Strategy. The district has many socio/economic problems such as unemployment, poor health and anti-social behaviour, but unlike neighbouring districts, it must find additional resources to deal with these issues.

Cultural and economic development linkages between regional and local levels are played out at the County Durham sub-regional partnership, CDSP (County Durham Strategic Partnership), and every district authority is a member. There are many tensions between the county and the districts and two key issues have recently surfaced. First, the decision to allocate $£ 250,000$ to conduct a City of Durham Visioning exercise has led some of the districts to lodge complaints, and the recent Referendum on Regional Assemblies and local government re-organisation has exacerbated the delicate relationships between the levels of government. Officers and members of the City Council are placing a lot of importance on the Visioning exercise, but without additional external funding or stimulation in the economic base, the City remains vulnerable.

Internally, the development of the City 's Leisure Strategy has stimulated the need for an Economic Development Strategy, and though each has some reference to culture and tourism there is little evidence of 'joining-up' the approaches to this service area. Each strategy has been developed in isolation, and there is a strong case to review the departmental structure and bring together EDU, Leisure and cultural/tourism services. If cultural and tourism services are so vital to economic growth, as has been argued elsewhere, there is a strong case for merging these disparate departments. However, the importance placed on these sectors, in the absence of manufacturing and heavy industries, leads to a view that tourism, arts and sport may be the saviour of local economies. Officers and members at district and county levels of government are keen to support the growth of these sectors, without any real evidence that can fill the gaps or shortfalls created by the slowdown in economic growth in traditional sectors.

Clustering is a key regional and sub-regional objective, but there has been little in the way of targeting or prioritisation. The City and the County has a very diverse economic base, and few clusters of creative and cultural activities, though there are plans to develop these industries to support the plans for the City. Heritage, tourism, and cultural and sporting activities have been identified 
as areas for future growth, but there is no data to support these claims (other than lots of regional and sub-regional rhetoric that in the absence of growth in other sectors of the economy, these areas will produce growth.

A Tourism project at the City (working with local colleges to provide skills and knowledge base for future creative sectors) and the Creative Business Support initiative are examples of excellent practice. There are also some very good examples of community enterprises within the tourism and cultural sectors, but little information, other than anecdotal data is available, so the City is currently engaged in assessing the levels of activity in this area (most of the activity has been developed in SRB schemes, and have yet to be evaluated and properly measured for sustainability).

Three key barriers still prevent creative and cultural development at the district level. Firstly, business support for all sectors (including tourism, cultural, creative and sporting) is still organised around the existing infrastructure, and this means that anyone who requires advice, funding or premises to set up in business still needs to apply and be assessed on certain pre-determined criteria. By continuing to operate the business support in terms of physical needs and the provision of incubator premises, the City is failing to be entrepreneurial in designing business support to ' reach out' to communities and stimulate growth within existing social networks and linkages. It is clear that entrepreneurship can flourish within social worlds, and the City may need to review existing properties and develop linkages into the villages across the district to evaluate how best to stimulate entrepreneurship. There are many under-used properties across the district, and it is recommended that the City council carries out an assessment of current and future needs. This review could identify under utilised resources, and suggest re-deployment into more innovative business support mechanisms.

Secondly, the City Council has no dedicated funding officer capable of drawing in external sources of finance. This is an imperative, especially in the creative and cultural fields. The City has benefited from various external funds, and some of it has impacted on business development within social enterprise, tourism and cultural sectors, but without some co-ordinated effort at fund raising, many projects are time-dependent and sustainability remains questionable. A more strategic approach to fund raising could improve the availability of finance, and help to stimulate future activities. City council officers and members are placing a lot of faith in the Visioning exercise, and important as this is to future activities, they need to evaluate other funding sources to stimulate activity.

Thirdly, there is a lot of activity across the district, and some excellent examples of entrepreneurialism, but without a thorough review of skills and competences of officers and lay people, there is no way of knowing how many activities in communities are focused on tourism, creative, cultural and sporting sectors. Without this basic data, the economic development unit will continue 
to provide business support in the time-honoured fashion, when in fact some of the SRB activities in deprived villages seem to offer useful models of community enterprise. Anecdotal information can be useful, but it needs to be supported by systematic data collection, so that support can more effectively targeted on community development and community enterprise activities.

\section{Conclusion}

If creative, cultural, tourism and sporting activities are so important to the health of the City, the county and the NE region, the findings on which this paper are based suggest that clearer targeting and prioritisation of these sectors should identify specific areas for growth and development. Moreover, the different levels of governance need to align more closely their objectives within this policy domain. Without such co-ordination, each level of governance will continue to simultaneously duplicate or leave gaps in coverage. The demise of heavy industry, the absence of a strong manufacturing base, a preponderance of service and public sector activities, coupled with a diverse and unsustainable SME sector, has left the City, the County and the Region vulnerable to the vagaries of global capital shifts, and continually at the behest of central government handouts. The NE region has a massive structural legacy to cope with, and though cultural and creative elements of the economic base offer some hope for the short-term future, there are many problems to be overcome as the region attempts to adapt to a post-Industrial future.

\section{References}

Backlund A-K and Sandberg A (2002), 'New Media Industry Development: Regions, Networks and Hierarchies - Some Policy Implications, Regional Studies, Vol.36, No.1, February, pp.87-93

Centre for Urban and Regional Development (CURDS) (2003), Mapping the Cultural and Creative sectors in the North East, University of Newcastle, City of Durham (2004), The Vision is here: City of Durham Community Plan Right Here, Right Now, City of Durham Economic Development Department, City Council, Durham.

City of Durham (2001), Best Value Review: Tourism, City of Durham Economic Development Department, City Council, Durham.

Coaffee J and Shaw T (2003), Regional experiences of sports-led regeneration. Northern Economic Review, Vols.33/34, Spring, pp.45-65

Cockerill T, Liddle J and Southern A (2000), 'Changes to the North East regional-local dynamic', Public Policy and Administration, Vol. 15, No.2, pp.110-126

County Durham Cultural Strategy (2002), Yeast in the dough, County Durham Cultural Partnership, Durham County Council.

County Durham Economic Partnership (2004) Update Delivery Plan 2004/5, County Durham Economic Partnership, Durham County Council. 
County Durham Strategic Partnership (2003), Strategic Vision for County Durham, Durham County Council.

Creigh-Tyte and Thomas B (1989), 'Tourism Fact Sheets: Employment: Northumbria and sightseeing in the UK', in Selwood S (Ed.), The UK Cultural Sector, Policy Studies Institute.

Department for Culture, Media and Sports (DCMS) (2001), Mapping Document for Creative Industries

Grant O (2003), 'The role of central and regional government in shaping creativity, culture and regional renewal: the role of DCMS and the NE Regional Cultural Consortium', unpublished paper presented to a seminar of the Regional Studies Association, Northern Branch, 8th April.

Gunton T (2003), 'Mega-projects and regional development: Pathologies in project planning', Regional Studies, Vol.37, No.5, pp.505-521

Hudson R, Sadler D and Townsend A R (1992), 'Employment change in the UK steel closure areas during the 1980s; Policy implications and lessons from Scotland'. Regional Studies, Vol.26, No.7, pp.633-646

Johnson P and Thomas B (1992), Tourism, museums and the local economy: the economic impact of the North of England Open Air Museum, Edward Elgar

Journal Newspaper 10.11.2001

Journal Newspaper 28.12.2001

Journal Newspaper 28.12.2001

Journal Newspaper 28.12.2001

Jowell T (2003) Edge-Creative Business Forum, London.

OPCS, (1999), 'Employment in the Cultural Sector by Industry and Occupation', Labour Force Survey, Spring, The Stationery Office.

OPCS, (1995), 'Employment in the Cultural Sector by Industry and Occupation', Labour Force Survey, Spring, The Stationery Office.

Liddle J (2001) 'RDA s, Sub-regional partnerships and local regeneration', Local Economy, Vol.16, No.4, pp.312-323

Liddle J (2004) A Leisure Strategy for the City of Durham, Durham City Council

Liddle J (forthcoming) An Economic Development Strategy for the City of Durham, Durham City Council.

Liddle J and Townsend A R (2003) 'Reflections on the development of Local Strategic Partnerships', Local Governance, Vol.29, No.1, pp.37-54

Northumbria Tourist Board (1999) Annual Report, Durham, UK

Oakley R, Kipling $M$ and Wildgust S (2001) 'Clustering among firms in the non-broadcast visual communications (NBVC) sector’, Regional Studies, Vol.35, No.5, July, pp.401-415

One North East (1999 and 2002), Realising Our Potential: The Regional Economic Strategy for the North East of England, One North East. 
Spilling O R (1996) 'Mega event as a strategy for regional development: the case of the 1994 Lillehammer Winter Olympics', Entrepreneurship and Regional Development, Vol.8, pp.321-343

Storey, D J (1994), Understanding the small business sector, Routledge

Thomas, R and Long, J (2000), 'Improving competitiveness: critical success factors for tourism development', Local Economy, Vol.13, No.2, pp.313328.

Throsby, C D (2001), Economics and culture, Cambridge University Press.

Tyneside Vision (2001), The Arts in Tyneside, Newcastle Upon Tyne, Journal Newspaper: Special Edition

Usherwood P, Beach J \& Morris C (2000), Public Sculpture of N E England, Liverpool, Liverpool University Press 